\title{
Mechanical and Durability Studies on Ficus exasperata Leaf Ash Concrete
}

\author{
K. S. Elango, ${ }^{1}$ B. Prabu, ${ }^{2}$ S. Sathish, ${ }^{3}$ Alagar Karthick ${ }^{D},{ }^{4,5}$ V. Sampathkumar, ${ }^{6}$ \\ Sanjeev Kumar, ${ }^{7}$ V. Mohanavel $\mathbb{D}^{,},{ }^{8}$ M. Ravichandran $\mathbb{D}^{9},{ }^{9}$ M. Muhibbullah $\mathbb{D},{ }^{10}$ \\ and Sameh M. Osman ${ }^{11}$ \\ ${ }^{1}$ Department of Civil Engineering, KPR Institute of Engineering and Technology, Coimbatore 641407, Tamil Nadu, India \\ ${ }^{2}$ Department of Civil Engineering, Sona College of Technology, Salem 636005, Tamil Nadu, India \\ ${ }^{3}$ Department of Mechanical Engineering, KPR Institute of Engineering and Technology, Coimbatore, Tamil Nadu, India \\ ${ }^{4}$ Renewable Energy Lab, Department of Electrical and Electronics Engineering, KPR Institute of Engineering and Technology, \\ Coimbatore 641407, Tamil Nadu, India \\ ${ }^{5}$ Departamento de Quimica Organica, Universidad de Cordoba, Edificio Marie Curie (C-3), Ctra Nnal IV-A, Km 396, E14014, \\ Cordoba, Spain \\ ${ }^{6}$ Department of Civil Engineering, Sathyabama Institute of Science and Technology, Chennai 600119, Tamil Nadu, India \\ ${ }^{7}$ Department of Civil Engineering, Graphic Era Deemed to Be University, Bell Road, Clement Town 248002, Dehradun, \\ Uttarakhand, India \\ ${ }^{8}$ Centre for Materials Engineering and Regenerative Medicine, Bharath Institute of Higher Education and Research, \\ Chennai 600073, Tamil Nadu, India \\ ${ }^{9}$ Department of Mechanical Engineering, K. Ramakrishnan College of Engineering, Trichy 621112, Tamil Nadu, India \\ ${ }^{10}$ Department of Electrical and Electronic Engineering, Bangladesh University, Dhaka 1207, Bangladesh \\ ${ }^{11}$ Chemistry Department, College of Science, King Saud University, P.O. Box 2455, Riyadh 11451, Saudi Arabia
}

Correspondence should be addressed to M. Muhibbullah; m.muhibbullah@bu.edu.bd

Received 23 October 2021; Revised 31 December 2021; Accepted 3 January 2022; Published 20 January 2022

Academic Editor: Wenjie Ge

Copyright $\odot 2022$ K. S. Elango et al. This is an open access article distributed under the Creative Commons Attribution License, which permits unrestricted use, distribution, and reproduction in any medium, provided the original work is properly cited.

This paper reports the effect of snake grass (SG) fibers in Ficus exasperata Leaf Ash (FELA) concrete. Snake grass fibers of percentages $0.5,1,1.5$, and 2 were used in this investigation. Tests of compressive strength, split tensile strength, and flexural strength and durability studies of salt resistance, sulphate resistance, and impact energy resistance were determined, and the test results are discussed in detail. Test results revealed that FELA ash of 15\% replacement in cement showed remarkable binding property. Moreover, incorporation of snake grass fiber in concrete improves the strength, postcracking resistance, and energy absorption. It is also observed that $1.5 \%$ snake grass fiber incorporation in concrete exhibited better strength properties and energy absorption property than $0.5 \%$ and $1 \%$. Also, beyond $1.5 \%$, there is significant reduction in workability property. Regardless of durability property, the mix containing $1.5 \%$ snake grass fiber has shown better resistance against durability when compared with other mixes. It is also observed that penetration of chloride and sulphate ions made slight deterioration at sharp edges. Moreover, test results revealed that applications of FELA concrete with snake grass fiber can be effectively expanded in the construction industry.

\section{Introduction}

Concrete is the most widely used material next to water all over the world. The construction activity can be enhanced by focusing attention towards sustainability in addition to performance and functional ability. The main objective of the sustainable growth is to ensure the benefits for future generation without affecting the needs of the present generation $[1,2]$. Binder is an essential material that combines some materials together to develop a cohesive mechanically 
or chemically by adhesion or cohesion. In construction work, Portland cement is used as a binder in concrete which holds aggregates together [3]. Portland cement can be categorized into various types of cement according to the raw materials used and use of additives and adjustment of chemical composition. In fact, Ordinary Portland Cement (OPC) is the most important type which is commercially available everywhere and another choice known as Portland Pozzolana Cement (PPC) is increasingly in use in this decade due to its high performance [4]. Infrastructural development makes concrete be used in wide applications because of its enhanced compressive strength which is an added advantage. It also has few limitations such as lack in toughness and lesser tensile strength. During application of load, occurrence of cracks is observed and the crack scale is in different extent under every magnitude of load. Mechanical and durability properties of the concrete have improved when concrete is blended with fly ash, lime stone powder, and rice husk ash in the percentage of 20, 10, and 5 [1]. At fracture point of view, concrete with no reinforcement has demonstrated lesser tensile strength and minimal strain [2]. Concrete brittleness gets weakened when crumb rubber content is increased inside concrete [5]. Higher ductility and toughness have been observed in Engineered Cementitious Composite (ECC). The volume of fiber addition by $2 \%$ produces $3 \%$ increment in maximum tensile strain [6-8]. ECC with nonexistence of coarse aggregate has improved brittleness owing to the presence of coarse aggregate but affects the fiber distribution in concrete [9]. Fiber is a tiny material which acts as reinforcing element in concrete. The parameter aspect ratio (length to its diameter) illustrates the shape of fiber and aspect ratio is typically ranging from 20 to 150. Fibers are broadly classified as metallic fibers, mineral fibers, synthetic fibers, and natural fibers. Fibers such as low carbon steel, stainless steel, galvanized iron, and aluminum are belonging to metallic fiber category while asbestos, glass, and carbon come under the category of mineral fibers. Synthesized polymers of tiny molecules are bonded together to form synthetic fibers and few synthetic fibers are polyester, nylon, polypropylene, and polyethylene. Natural fibers are formed due to geological processes or from plants and animal bodies. Apart from static loads, concrete structure is also subjected to impact loads due to earthquakes, machine vibration, natural calamities, and so on. Impact load in the structures makes concrete fail suddenly but when fibers are incorporated in the concrete structure it overcomes the brittle failure $[3,10]$. Also, energy absorption property increased with inclusion of silica fume materials, steel fibers, and polypropylene fibers. Hybrid fibers result in overall improvement and higher performance and produce better mechanical properties [11]. The presence of carbohydrate content in cementitious material improves the service life of structures and secondary cementitious material with silica reaction improves strength in concrete [12]. 15\% replacement of Ficus exasperata Leaf Ash shows better mechanical property and when the replacement percentage has increased, strength gets decreased [4, 13-16]. Increased compressive strength of cement paste enhances the compressive strength of the concrete and addition of nanosilica
(NS) modifies the microstructure property of hardened cementitious paste [17]. Inclusion of mineral admixtures in high volume boosts the concrete strength. Specimens cured under steam curing and high pressure steam curing possess improved compressive strength compared to other curing conditions [18]. Better filler property is observed in Ennore sand having grade I (70\%) and grade II (30\%) [19]. Fiber orientation influences the mechanical properties of the concrete [20]. Steel fibers packed with high density accomplish high compressive strength [21]. More researches are being carried out utilizing various fibers like steel fibers, polypropylene fibers, and carbon fibers. Nevertheless, limited researches have been carried out using steel fiber and snake grass fibers. In this present study, an attempt has been made to investigate the mechanical and impact resistance properties of concrete containing different percentages of snake grass hybrid fibers and feasibility of using Ficus exasperata Leaf Ash in concrete as a partial replacement for Ordinary Portland Cement (OPC) [22]. Steel fiber addition in concrete improves impact energy absorption capacity [23]. Supplementary cementitious materials (SCMs) such as rice husk ash, fly ash, bottom ash, and ground granulated blast furnace slag in concrete increase strength and durability properties and they also make concrete more economical and environmentally friendly. Inclusion of steel fibers increases the ductility and energy absorption property in concrete. In addition, addition of various fibers in the concrete exhibits various kinds of action in the behaving property [24]. Three kinds of actions include toughening, reinforcing, and anticracking. Upon environmental exposure, cracks formation takes place in the structures. Major cracks formed in the structure are of shrinkage cracks. Those cracks can be arrested and the action of preventing or arresting the crack generation in the structures is called anticracking. Moreover, mechanical properties of the concrete can be improved by inclusion of the fibers and the effect caused due to cracks can be minimized or arrested. The action taking place due to this effect is known as reinforcing action. Further, it also increases the toughness property of the concrete and it refers to toughening action. During the use of steel fibers, compaction using vibrator can be preferred for even distribution of fibers which can increase the concrete density that indirectly improves the mechanical properties of the concrete. In order to improve the ductile property in concrete, fibers can be added in optimum percentage [25]. Volume addition of fibers by $2 \%$ increases the tensile strength of concrete by $3 \%$. Engineered Cement Composite (ECC) incorporation instead of coarse aggregates enhances the fiber distribution in the concrete. Fly ash (FA) addition in ECC greatly reduces the emission percentage of carbon dioxide and also improves the toughness and ductility. It is noticed that FA addition greatly decreases the heat of hydration and it also makes the concrete economical [26].

\section{Materials}

2.1. Cement and Aggregates. Ordinary Portland Cement (OPC) grade 53 with specific gravity of 3.10, fineness of $3.05 \%$, and consistency of $31 \%$ has been used in this study. 
Initial setting time and final setting time have been recorded and it is found to be 85 and 290 minutes, respectively. Crushed blue granite metal (coarse aggregate (CA)) having a specific gravity of 2.72 and $\mathrm{M}$-sand (fine aggregate (FA)) with a specific gravity of 2.65 are used. OPC grade- 53 cement and coarse aggregates were purchased in APAT Crushers, Erode, Tamil Nadu, India.

2.2. Fibers. Snake grass fibers (Sansevieria ehrenbergii) having a diameter of $45 \mu \mathrm{m}$ and tensile strength ranging $240-450 \mathrm{MPa}$ have been used in this present study (Figure 1). Furthermore, to know the morphological behavior, scanning electron microscope study on snake grass fiber has been carried out at PSG College of Technology, Coimbatore, Tamil Nadu, India (Figure 2). The scanning electron microscope (SEM) image revealed that the shape of the fiber cross section is round and it is mainly used to determine the strength of the fiber. The snake grass fiber has very low density associated with other biofibers like flax, sea grass, and oil palm but has higher density than elephant grass, ramie, and petiole bark. The transverse and the longitudinal direction of fiber diameter are around $20-240 \mu \mathrm{m}$ and 25-250 $\mu \mathrm{m}$ using optical microscopy.

2.3. Ficus exasperata Leaf Ash (FELA). Ficus exasperata leaf (sand paper tree) was gathered from Palakkad district, Kerala (Figure 3). Gathered leaves were dried at natural sunlight and heated over at muffle furnace at a temperature of $500^{\circ} \mathrm{C}$ and while heating, the ash was subjected to calcination. The ash obtained after calcination was sieved through 90 microns $(\mu)$ to attain the required fineness. In order to investigate the presence of chemical compounds in FELA, chemical properties have been studied at Sona College of Technology, Salem, Tamil Nadu, India. FELA comprises $81.45 \% \mathrm{SiO}_{2}, 5.88 \% \mathrm{CaO}$, $3.78 \% \mathrm{SO}_{3}, 3.02 \% \mathrm{~K}_{2} \mathrm{O}, 1.85 \% \mathrm{Al}_{2} \mathrm{O}_{3}$, and $1.95 \% \mathrm{Fe}_{2} \mathrm{O}_{3}$ [4]. The chemical test results proved that FELA can be effectively used as supplementary cementitious material since it satisfies the requirement for cementitious material through $\mathrm{SiO}_{2}$ percentage in the ash content. Furthermore, to observe the morphological behavior of FELA, scanning electron microscope test has been carried out on calcined Ficus exasperata Leaf Ash at Karunya University, Coimbatore, Tamil Nadu, India. The SEM image of FELA proved that the particles present are in spherical and round shape (Figure 4).

2.4. Mix Design. The grade used in this present study is M25 and the mix design has been carried out in accordance with IS 10262-2009 [27, 28]. Mix produced without snake grass fiber and Ficus exasperata Leaf Ash is considered as conventional control mix and designated as CC. Four mixes were prepared with different percentages of snake grass fiber. The percentage of snake grass fiber used was $0.5,1,1.5$, and 2 by concrete volume. In order to prepare FELA-SG concrete, coarse aggregate and fine aggregate are mixed thoroughly in dry state for 60 seconds. FELA ash (15\% weight of total cement) was added with the dry mix and thorough mixing was carried out for two minutes. In continuation with the

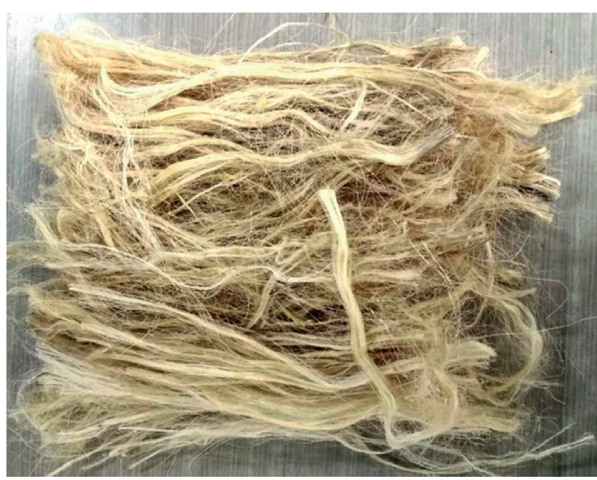

FIgURE 1: Extracted fiber of Sansevieria ehrenbergii plant.

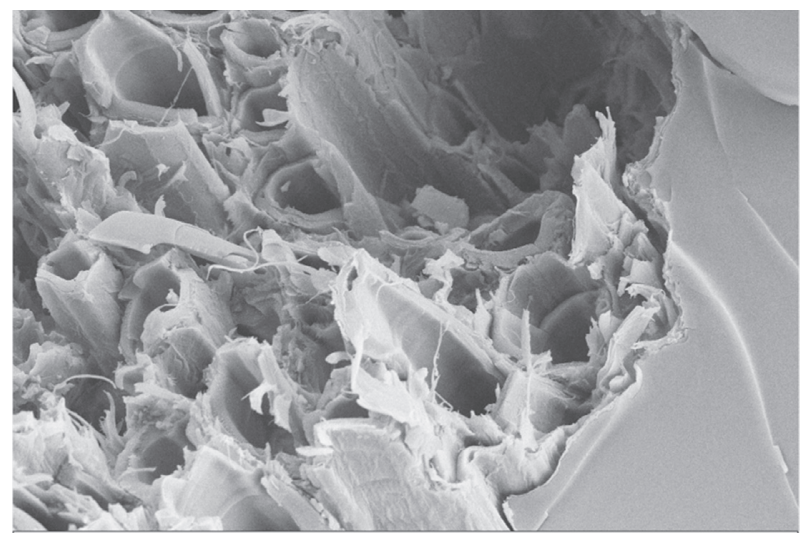

Figure 2: Scanning electron microscope image of Sansevieria ehrenbergii fiber.

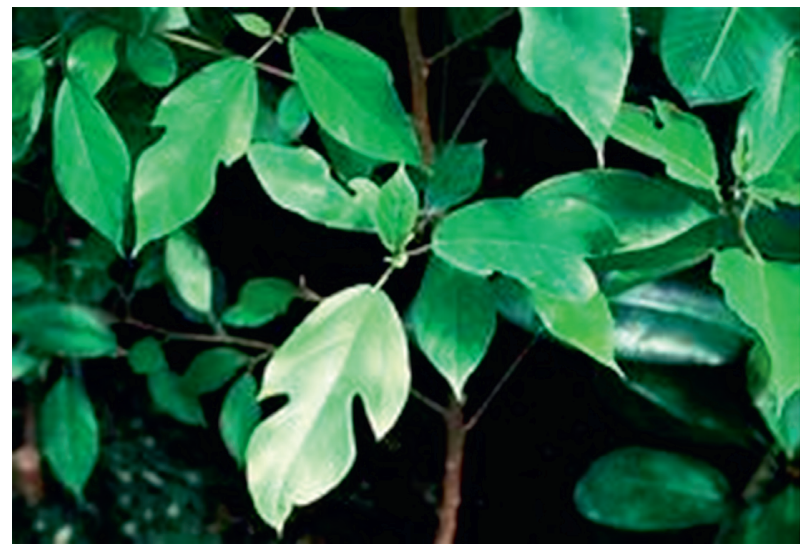

Figure 3: Ficus exasperata leaf before drying process.

process, potable water available at KPR Institute of Engineering and Technology (KPRIET) college laboratory was added and homogenously mixed for five minutes. Snake grass fibers of specified amount required as per mix design were added and mixed carefully in order to achieve consistent distribution inside the concrete. Table 1 shows the mix proportion achieved for various mixes. Mix ID MSG represents the mix produced with snake grass fiber and the value mentioned in suffix of each mix ID shows the percentage of snake grass fiber used. 


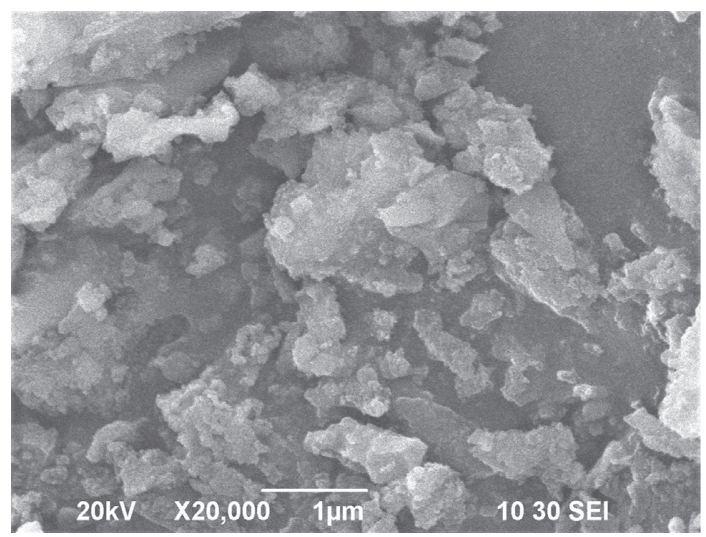

FIgURE 4: Scanning electron microscope image of calcined Ficus exasperata Leaf Ash.

TABLE 1: Mix proportion of various mixes.

\begin{tabular}{|c|c|c|c|c|c|c|c|c|}
\hline \multirow[t]{2}{*}{ Mix ID } & \multicolumn{2}{|c|}{ Cement } & \multicolumn{2}{|c|}{ FELA } & \multicolumn{2}{|c|}{$\begin{array}{l}\text { Snake grass } \\
\text { fiber }\end{array}$} & \multirow[t]{2}{*}{ Fine aggregate $\left(\mathrm{kg} / \mathrm{m}^{3}\right)$} & \multirow[t]{2}{*}{ Coarse aggregate $\left(\mathrm{kg} / \mathrm{m}^{3}\right)$} \\
\hline & $\%$ & $\mathrm{~kg} / \mathrm{m}^{3}$ & $\%$ & $\mathrm{~kg} / \mathrm{m}^{3}$ & $\%$ & $\mathrm{~kg} / \mathrm{m}^{3}$ & & \\
\hline $\mathrm{CC}$ & 0 & 428 & 0 & - & 0 & - & 518.50 & 1195.60 \\
\hline MSG0.5 & 85 & 364 & 15 & 64 & 0.5 & 2.15 & 518.50 & 1195.60 \\
\hline MSG1.0 & 85 & 364 & 15 & 64 & 1 & 4.30 & 518.50 & 1195.60 \\
\hline MSG1.5 & 85 & 364 & 15 & 64 & 1.5 & 6.45 & 518.50 & 1195.60 \\
\hline MSG2.0 & 85 & 364 & 15 & 64 & 2 & 8.60 & 518.50 & 1195.60 \\
\hline
\end{tabular}

\section{Experimental Program}

3.1. Mechanical Properties. Totally 30 cubes $(150 \mathrm{~mm} \times 150 \mathrm{~mm} \times 150 \mathrm{~mm})$, cylinders $(150 \mathrm{~mm}$ in diameter and $300 \mathrm{~mm}$ in height), and beams $(100 \mathrm{~mm} \times 100 \mathrm{~mm} \times 500 \mathrm{~mm})$ are cast to study the compressive, split tensile, and flexural strength of concrete made with FELA and SG fibers. Among all the tests, compressive strength test has more importance because, in most of the structural applications, concrete is subjected to compressive stress rather than tensile stress. The load was applied gradually without shock and continuously increased at the rate of $14 \mathrm{~N} / \mathrm{sq} . \mathrm{mm} / \mathrm{min}$ until achieving the resistance of the specimen. Average of three cubes was tested for each mix to study the compressive strength properties at the age of 7 and 28 days. Regardless of split tensile strength, the cylindrical specimen was kept horizontally in compression testing machine between the platens so that applying of load leads to failure of the cylindrical specimen along the vertical diameter. It should also be ensured that upper platen is parallel with lower platen. Load on the specimen was applied gradually at a nominal rate in the range of $1.2 \mathrm{~N} / \mathrm{sq} . \mathrm{mm} / \mathrm{min}$. Flexural strength was determined by keeping the specimen mounted on the two roller beds of $38 \mathrm{~mm}$ diameter and the center to center distance between the two rollers was kept as $400 \mathrm{~mm}$. The load was applied at the compression surface of the specimen through the couple of rollers mounted above at the distance of $133 \mathrm{~mm}$ from center to center. Load was applied uniformly at the rate of $1.80 \mathrm{kN} / \mathrm{min}$ till the specimen gets failed $[29,30]$.
3.2. Durability Properties. The durability tests such as resistance against salt and sulphate attack were conducted on the concrete cube specimens of $100 \mathrm{~mm} \times 100 \mathrm{~mm} \times 100 \mathrm{~mm}$. The 28 -day cured cube specimens were dried in room temperature and the weight $\left(W_{1}\right)$ of the cubes was measured. Then, the specimens were immersed in $\mathrm{NaCl}$ salt solution with $3.5 \%$ concentration (equivalent to sea water). Chloride solution was prepared in plastic tubs and covered temporarily to arrest the evaporation and dust formation. The $\mathrm{pH}$ value of the solution was monitored periodically and the solution was replaced every month. Specimens were also tested against sulphate attack. The test procedure was the same as that of chloride $(\mathrm{NaCl})$ attack. The specimens were immersed in magnesium sulphate $\left(\mathrm{MgSO}_{4}\right)$ solution with $5 \%$ concentration. $\mathrm{MgSO}_{4}$ was selected since it is more aggressive than $\mathrm{CaSO}_{4}$. The immersed specimens in salt and sulphate solution were taken out at the age of $28,56,90$, and 180 days for examination. The examinations such as visual appearance, change in weight $\left(W_{2}\right)$, and residual compressive strength studies were done to know the properties of the concrete subjected to salt attack.

Percentage of loss in weight can be calculated using the following equation:

$$
\text { percentage of weight loss }(\%)=\frac{W_{1}-W_{2}}{W_{1}},
$$

where $W_{1}$ is the specimen weight before exposure to solution in $\mathrm{kg}$ and $W_{2}$ is the specimen weight before exposure to solution in $\mathrm{kg}$. 
3.3. Impact Energy Test. The cylindrical specimen of size $150 \mathrm{~mm}$ in diameter and $64 \mathrm{~mm}$ in height was cast to know the impact energy absorption capacity $[24,31]$. This test was conducted in accordance with ACI 544.2R-89 (reapproved in 2009) [32] at the age of 28 days and 56 days. Base plate with lugs was used to support the specimen cast with PVC pipe of $63.5 \mathrm{~mm}$ in diameter which was kept above the specimen through steel ball of $63.5 \mathrm{~mm}$ which falls on the specimen. The number of blows taken for the first crack and final failure crack was noticed and impact resistance energy has been calculated using (2). Test setup used for determining impact energy is represented schematically in Figure 5.

$$
E_{\text {imp }}=\text { N.m.g.h, }
$$

where $E_{\text {imp }}$ is the impact energy in $J, N$ is the number of blows, $m$ is the mass of drop hammer in $\mathrm{kg}, g=9.81 \mathrm{~m} / \mathrm{s}^{2}$, and $h$ is the releasing height of drop hammer in $m$.

\section{Results and Discussion}

4.1. Mechanical Properties. Mechanical properties such as compressive strength, split tensile strength, and flexural strength were performed and test results are tabulated in Table 2. Also, statistical analysis for all the mixes was also done to know the normal distribution of results.

Test results at the age of 28 days revealed that the mix made with $0.5 \%, 1 \%$, and $1.5 \%$ snake grass fiber exhibited higher strength properties than the conventional control mix. When compared to CC, compressive strength of FELA concrete increased by $11.11 \%, 22 \%$, and $22.9 \%$ for the mixes having $0.5 \%, 1 \%$, and $1.5 \%$ SG fibers. This can be attributed to the fact that the addition of fibers made significant effect on improvement of test results. It has also been observed that when the SG fiber addition is increased beyond $2 \%$, there has been a decrease in compressive strength properties. The decrement of compressive strength is due to poor workability, when high percentage fibers are added, which indirectly affected the cohesiveness and led to balling effect. However, the mix with suitable admixture for workability could show remarkable strength properties with $2 \%$ SG fiber addition [33]. Regardless of split tensile strength, the trend observed in compressive strength property is as follows. The mix made with $0.5 \%, 1 \%$, and $1.5 \%$ has shown $5.17 \%, 21.3 \%$, and $31 \%$ higher split tensile strength than the conventional control mix. Furthermore, 5.52\%, 13.2\%, and $17.4 \%$ lesser flexural strength could be observed compared to conventional control mix having $0.5 \%, 1 \%$, and $1.5 \%$ SG fibers. In both cases, when the percentage addition of SG fibers was increased by $1.5 \%$, there was a gradual decrease in strength properties. This is due to deprived workability. Performed statistical analysis proved that better distribution of test results are noticed on all the test parameters. Test results arrived are graphically Figure 6 represented Figure 7 in Figure 8. In addition, regression analysis has also been carried out to understand the relationship between the mechanical property and the percentage of fiber addition in the concrete and the same is shown in (3)-(5). Moreover, to measure the fitness of the curve, $R^{2}$ value is determined and mentioned in

$$
\begin{aligned}
& R^{2}=0.952, \text { fck }(28)=27.90+10.34 \mathrm{sg}-3.14 \mathrm{sg}^{2}, R^{2}=0.952, \\
& R^{2}=0.953, \text { fst }(28)=2.80+1.072 \mathrm{sg}-0.35 \mathrm{sg}^{2}, R^{2}=0.953, \\
& R^{2}=0.950, \text { fct }(28)=3.58+0.73 \mathrm{sg}-0.22 \mathrm{sg}^{2}, R^{2}=0.950,
\end{aligned}
$$

where $\mathrm{fck}$ is the compressive strength at 28 days ( $\mathrm{MPa}$ ), fst is the split tensile strength at 28 days ( $\mathrm{MPa}$ ), fct is the flexural strength at 28 days $(\mathrm{MPa})$, and sg is the percentage of snake grass fiber (\%).

4.2. Durability Properties. Specimens subjected to salt and sulphate attack have been examined visually and mechanically. Test results revealed that the concrete produced with Ficus exasperata Leaf ash and snake grass fiber has better resistance against salt and sulphate attack and the results are presented in Table 3. Results compared were noticed at the age of 180 days. Test results demonstrated that, when compared to control mix, mix $\mathrm{MSG}_{0.5}$ shows 0.85 -fold lesser percentage of weight retention when subjected to salt attack solution. Similarly lesser percentage of weight retention was observed in the mixes made with 1.0 and $2.0 \%$ snake grass fibers. $\mathrm{MSG}_{1.5}$ has demonstrated 0.45 -fold increase in percentage of weight retention when compared to control mix. The same trend of results was observed in the specimens when subjected to magnesium sulphate attack solution. At the age of 180 days, residual compressive strength was determined. Test results exhibited that MSG $_{1.5}$ mix showed better retention in compressive strength than conventional control mix. The same trend was observed in percentage of weight retention property. Upon visual observation, all the mixes immersed in $\mathrm{NaCl}$ solution have no change in color whereas specimens which are soaked in $\mathrm{MgSO}_{4}$ solution showed slight whitish layer appearance. This can be attributed to the fact that displayed calcium in the cement matrix shows whitish appearance when immersed in magnesium sulphate solution. Moreover, slight deterioration at sharp edges observed is due to the effect of chemical solutions. The penetration of chloride and sulphate ions in the concrete mix makes the matrix bonding disintegrate and leads to deterioration at sharp edges and this occurred since edges contain mortar portion rather than concrete portion. It was also noticed that incorporation of FELA has magnanimous effect on improving the durability properties.

4.3. Impact Resistance Energy. Impact energy test results are noticed at the age of 28 days and 56 days and the results are shown in Table 4 and graphically represented in Figure 9. Test results revealed that the mix with $1.5 \%$ snake grass fiber showed higher impact energy resistance than the mix made with $0.5 \%$ and $1 \%$. It is also been noticed that when the percentage addition of fiber exceeds $1.5 \%$, there was a gradual decrement in impact energy property. This can be attributed to the fact that the increase in fiber content results in lesser workability and lesser impact energy property. This 

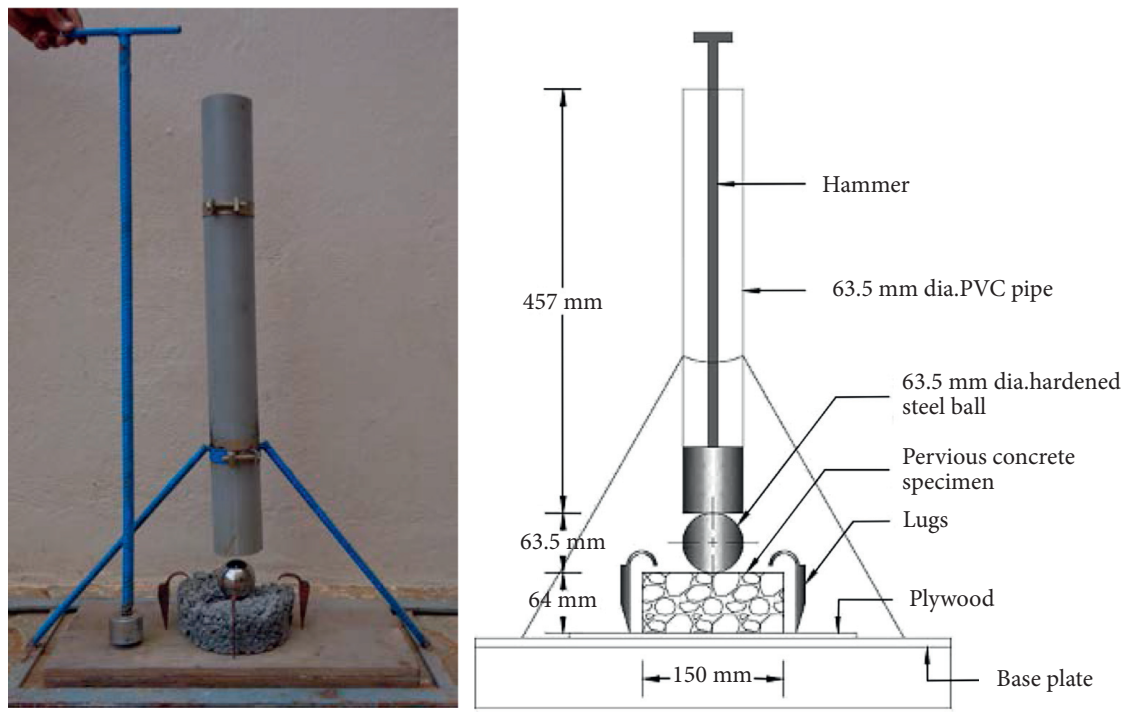

Figure 5: Impact energy test setup. (a) Figure. (b) Schematic figure.

TABLE 2: Strength properties of various mixes.

\begin{tabular}{|c|c|c|c|c|c|c|c|}
\hline \multirow[t]{2}{*}{ Mix ID } & \multirow[t]{2}{*}{ Age at testing } & \multicolumn{2}{|c|}{$\begin{array}{c}\text { Compressive strength } \\
(\mathrm{MPa})\end{array}$} & \multicolumn{2}{|c|}{$\begin{array}{l}\text { Split tensile strength } \\
(\mathrm{MPa})\end{array}$} & \multicolumn{2}{|c|}{$\begin{array}{c}\text { Flexural strength } \\
(\mathrm{MPa})\end{array}$} \\
\hline & & Mean & $\mathrm{SD}$ & Mean & SD & Mean & $\mathrm{SD}$ \\
\hline \multirow{2}{*}{$\mathrm{CC}$} & 7 & 20.50 & 1.51 & 1.95 & 0.18 & 3.10 & 0.33 \\
\hline & 28 & 28.35 & 1.38 & 2.90 & 0.23 & 3.62 & 0.43 \\
\hline \multirow{2}{*}{$\mathrm{MSG}_{0.5}$} & 7 & 23.20 & 1.03 & 2.35 & 0.17 & 3.27 & 0.29 \\
\hline & 28 & 31.50 & 2.03 & 3.05 & 0.24 & 3.82 & 0.26 \\
\hline \multirow{2}{*}{$\mathrm{MSG}_{1.0}$} & 7 & 25.35 & 0.74 & 2.60 & 0.14 & 3.40 & 0.25 \\
\hline & 28 & 34.85 & 1.79 & 3.52 & 0.24 & 4.10 & 0.30 \\
\hline \multirow{2}{*}{$\mathrm{MSG}_{1.5}$} & 7 & 28.25 & 1.01 & 2.94 & 0.05 & 3.65 & 0.10 \\
\hline & 28 & 37.50 & 1.28 & 3.80 & 0.18 & 4.25 & 0.35 \\
\hline \multirow{2}{*}{$\mathrm{MSG}_{2.0}$} & 7 & 26.50 & 1.00 & 2.60 & 0.20 & 3.50 & 0.37 \\
\hline & 28 & 35.50 & 1.88 & 3.42 & 0.33 & 4.12 & 0.45 \\
\hline
\end{tabular}

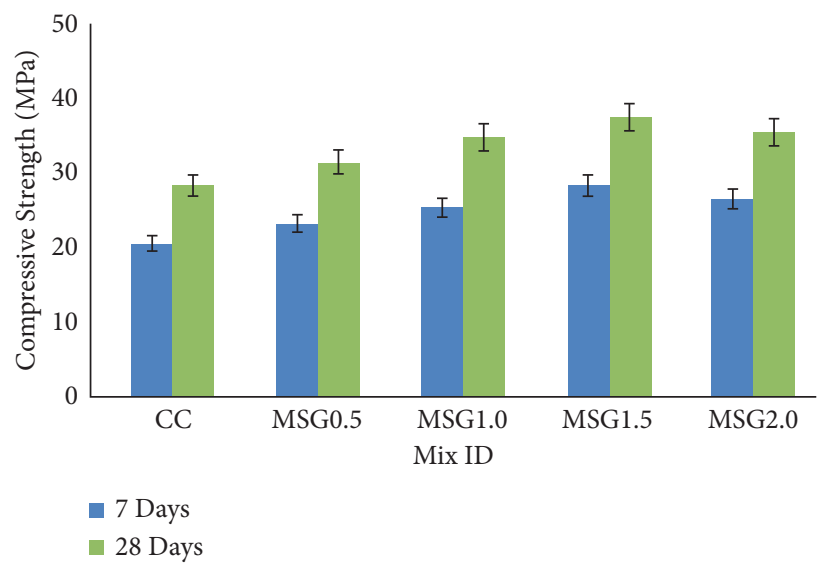

Figure 6: Compressive strength of various mixes.

same trend of results is observed in compressive strength property as well. It is evident that impact energy resistance has a direct relationship with compressive strength.
Specimens subjected to impact force are shown in Figure 10 and the observed failure pattern during failure crack is clearly visible. 


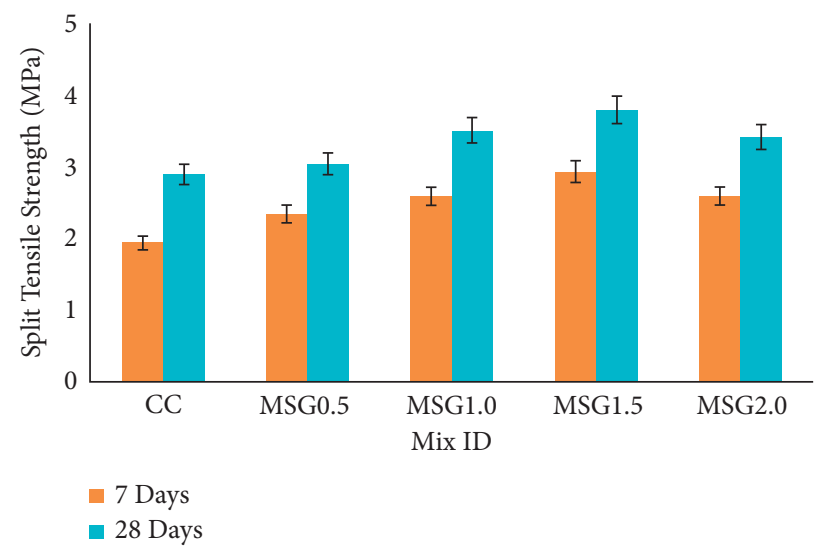

FIgURE 7: Split tensile strength of various mixes.

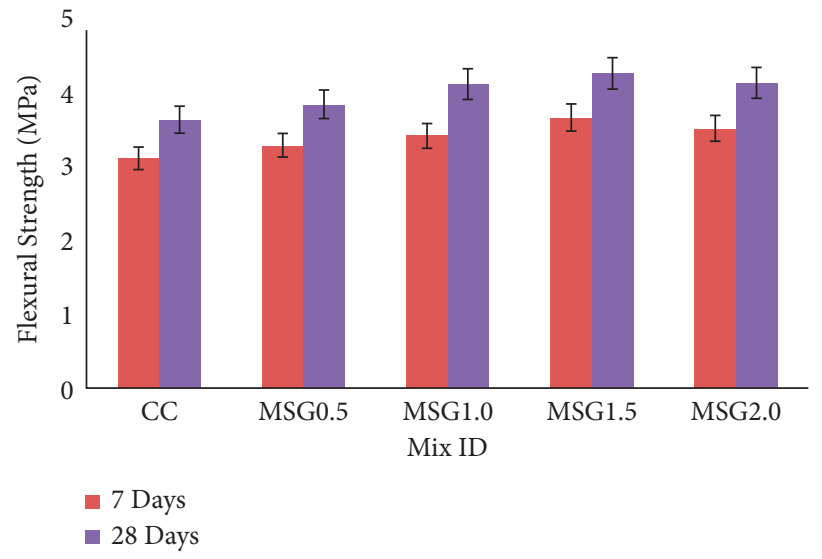

FIgURE 8: Flexural strength of various mixes.

TABLE 3: Durability properties of various mixes.

\begin{tabular}{llccc}
\hline Mix ID & \multicolumn{2}{c}{$\begin{array}{c}\text { Percentage of weight retention at } 180 \\
\text { days }\end{array}$} & \multicolumn{2}{c}{$\begin{array}{c}\text { Residual compressive strength at } 180 \\
\text { days (\%) }\end{array}$} \\
\hline CC & $\mathrm{NaCl}$ & $\mathrm{MgSO}_{4}$ & $\mathrm{NaCl}$ & 2.35 \\
MSG $_{0.5}$ & 97.48 & 97.15 & 2.52 & 2.40 \\
MSG $_{1.0}$ & 96.60 & 95.20 & 2.58 & 2.52 \\
MSG $_{1.5}$ & 96.65 & 95.70 & 2.85 & 2.78 \\
MSG $_{2.0}$ & 97.90 & 96.50 & 2.20 & 2.00 \\
\hline
\end{tabular}

TABLE 4: Impact energy of various mixes.

\begin{tabular}{|c|c|c|c|c|c|c|c|c|}
\hline \multirow{3}{*}{ Mix ID } & \multicolumn{4}{|c|}{ Number of blows $(\mathrm{N})$} & \multicolumn{4}{|c|}{ Impact energy $(\mathrm{Nm})$} \\
\hline & \multicolumn{2}{|c|}{28 days } & \multicolumn{2}{|c|}{56 days } & \multicolumn{2}{|c|}{28 days } & \multicolumn{2}{|c|}{56 days } \\
\hline & First crack & Failure crack & First crack & Failure crack & First crack & Failure crack & First crack & Failure crack \\
\hline$\overline{\mathrm{CC}}$ & 455 & 462 & 578 & 596 & 2040 & 2071 & 2591 & 2672 \\
\hline $\mathrm{MSG}_{0.5}$ & 467 & 478 & 586 & 602 & 2094 & 2143 & 2627 & 2699 \\
\hline $\mathrm{MSG}_{1.0}$ & 472 & 485 & 599 & 613 & 2116 & 2174 & 2685 & 2748 \\
\hline $\mathrm{MSG}_{1.5}$ & 488 & 493 & 610 & 621 & 2188 & 2210 & 2735 & 2784 \\
\hline $\mathrm{MSG}_{2.0}$ & 471 & 478 & 602 & 607 & 2112 & 2143 & 2699 & 2721 \\
\hline
\end{tabular}




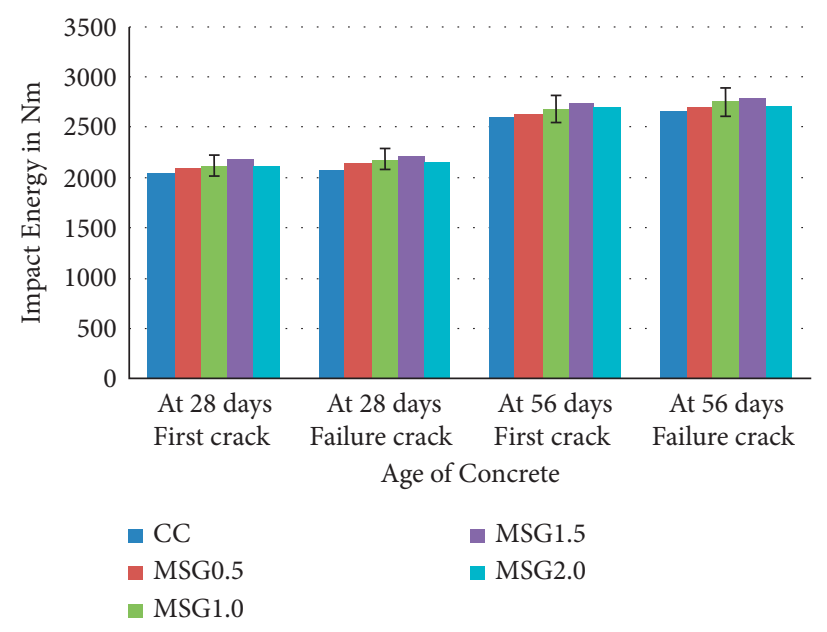

FIGURE 9: Impact energy of various mixes.
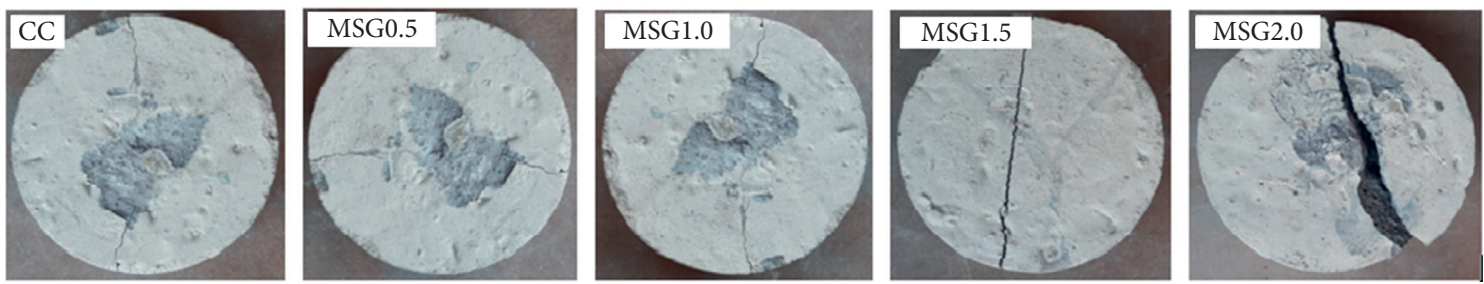

FIGURE 10: Specimens tested against impact force.

\section{Conclusion}

The mechanical properties such as compressive strength, split tensile strength, flexural strength, and impact energy resistance and durability properties such as salt resistance and sulphate resistance were demonstrated and the following conclusions are drawn:

(1) Ordinary Portland Cement replaced with 15\% of FELA has shown improved and excellent mechanical and durability properties. Furthermore, it is observed that chemical composition confirms the feasibility of using FELA as mineral admixture in concrete.

(2) Snake grass fibers, in addition to FELA concrete, showed remarkable mechanical and impact resistance properties. This can be attributed to the fact that round morphological structure influenced and improved strength properties which is confirmed by microstructural study.

(3) It was observed that concrete with $1.5 \%$ of snake grass fibers possessed higher strength and impact energy than concrete containing $0.5 \%$ and $1 \%$ snake grass fibers. $22.9 \%$ increase in compressive strength was noticed in $\mathrm{MSG}_{1.5}$ when compared to conventional control mix.

(4) There was a gradual decrease in strength and impact energy when addition of snake grass fibers exceeded $1.5 \%$. This can be attributed to the fact that when the amount of fiber addition increases, it shows lesser workability and results in decrease in strength and impact resistance property. The specimens with $15 \%$ of FELA and $1.5 \%$ of snake grass have demonstrated better performance in terms of mechanical properties and impact energy and also have better postcracking resistance than conventional control mix.

(5) Regardless of durability properties, among all mixes, $\mathrm{MSG}_{1.5}$ has demonstrated better strength and weight retention against chloride and sulphate solution attack. This can be attributed to the fact that concrete with $1.5 \%$ addition of SG fibers showed denser effect when compared to other mixes that would act as barrier medium for penetration of chloride and sulphate ions.

(6) From the test results, it was evident that concrete made with Ficus exasperata Leaf Ash as a partial replacement for cement showed better strength and durability properties and it can be used for sustainable construction practices.

\section{Data Availability}

The data used to support the findings of this study are included within the article.

\section{Conflicts of Interest}

The authors declare that there are no conflicts of interest regarding the publication of this article. 


\section{Acknowledgments}

Alagar Karthick gratefully acknowledges group FQM-383 from Universidad de Cordoba, Spain, for the provision of an honorary visiting research position in the group. This project was funded by the Researchers Supporting Project (no. RSP2021/405), King Saud University, Riyadh, Saudi Arabia.

\section{References}

[1] P. Kathirvel, V. Saraswathy, S. P. Karthik, and A. S. S. Sekar, "Strength and durability properties of quaternary cement concrete made with fly ash, rice husk ash and limestone powder," Arabian Journal for Science and Engineering, vol. 38, no. 3, pp. 589-598, 2013.

[2] K. S. Elango and V. Revathi, "Fal-G binder pervious concrete," Construction and Building Materials, vol. 140, pp. 91-99, 2017.

[3] K. S. Elango and V. Revathi, "Properties of PPC binder pervious concrete," International Journal of Advances in Engineering \& Technology, vol. 7, no. 2, pp. 444-448, 2016.

[4] K. S. Elango, P. R. Remya, D. Vivek, R. Gopi, and R. Saravanakumar, "Strength and durability studies on Ficus Exasperata leaf ash concrete," Materials Today Proceedings, vol. 37, no. 11, 2020.

[5] A. R. Khaloo, M. Dehestani, and P. Rahmatabadi, "Mechanical properties of concrete containing a high volume of tire-rubber particles," Waste Management, vol. 28, no. 12, pp. 2472-2482, 2008.

[6] V. C. Li, "On Engineered Cementitious Composites (ECC): a review of the material and its applications," Transportation Research Record Journal of the Transportation Research Board, vol. 2164, pp. 1-8, 2010.

[7] S. Wang, C. Wu, and V. C. Li, "Tensile strain-hardening behaviour of polyvinyl alcohol engineered cementitious composite (PVA-ECC)," ACI Materials Journal, vol. 98, no. 6, pp. 483-492, 2001.

[8] R. Dharmaraj, A. Karthick, G. K. Arunvivek et al., "Novel approach to handling microfiber-rich dye effluent for sustainable water conservation," Advances in Civil Engineering, vol. 2021, Article ID 1323472, 10 pages, 2021.

[9] M. A. Chowdhury, M. M. Islam, and Z. Ibna Zahid, "Finite element modeling of compressive and splitting tensile behavior of plain concrete and steel fiber reinforced concrete cylinder specimens," Advances in Civil Engineering, vol. 2016, pp. 1-11, Article ID 6579434, 2016.

[10] K. Khaloo, "Mechanical properties of normal to high strength steel fiber reinforced concrete," Cement, Concrete and Aggregates, vol. 18, pp. 92-97, 1996.

[11] M. Bentur, Fibre Reinforced Cementitious Composites, Taylor \& Francis, Oxfordshire, UK, 2007.

[12] R. Dharmaraj, G. K. Arunvivek, A. Karthick, V. Mohanavel, B. Perumal, and S. Rajkumar, "Investigation of mechanical and durability properties of concrete mixed with water exposed to a magnetic field," Advances in Civil Engineering, vol. 2021, Article ID 2821419, 14 pages, 2021.

[13] K. S. Elango and V. Revathi, "Infiltration and clogging characteristics of pervious concrete," Asian Journal of Civil Engineering, vol. 20, no. 8, pp. 1119-1127, 2019.

[14] L. Zheng, X. S. Huo, and Y. Yuan, "Strength, modulus of elasticity, and brittleness index of rubberized concrete," Journal of Materials in Civil Engineering, vol. 20, no. 11, pp. 692-699, 2008.

[15] F. Hernández-Olivares, G. Barluenga, M. Bollati, and B. Witoszek, "Static and dynamic behaviour of recycled tyre rubber-filled concrete," Cement and Concrete Research, vol. 32, no. 10, pp. 1587-1596, 2002.

[16] K. S. Elango, R. Gopi, C. Jayaguru, D. Vivek, R. Saravanakumar, and V. Rajeshkumar, "Experimental investigation on concrete beams reinforced with basalt fiber reinforced polymer bars," Materials Today Proceedings, vol. 45, no. 2, 2020.

[17] B. S. Mohammed, M. S. Liew, W. S. Alaloul, V. C. Khed, C. Y. Hoong, and M. Adamu, "Properties of nano-silica modified pervious concrete," Case Studies in Construction Materials, vol. 8, pp. 409-422, 2018.

[18] H. Yazici, "Effect of curing conditions on compressive strength of ultra high strength concrete with high volume mineral admixtures," Building and Environment, vol. 42, no. 5, pp. 2083-2089, 2007.

[19] P. R. Prem, B. H. Bharatkumar, and N. R. Iyer, "Influence of curing regimes on compressive strength of ultra high performance concrete," Sadhana, vol. 38, no. 6, pp. 1421-1431, 2013.

[20] J. Michels, "Matija Gams "Preliminary study on the influence of fibre orientation in fibre reinforced mortars", Građevinar, vol. 8, pp. 645-655, 2016.

[21] K. Wille, A. E. Naaman, S. El-Tawil, and G. J. Parra-Montesinos, "Ultra-high performance concrete and fiber reinforced concrete: achieving strength and ductility without heat curing," Materials and Structures, vol. 45, no. 3, pp. 309-324, 2011.

[22] K. S. Elango, D. Vivek, G. KrishnaPrakash, M. J. Paranidharan, S. Pradeep, and M. Prabhukesavaraj, "Strength and permeability studies on PPC binder pervious concrete using palm jaggery as an admixture," Materials Today Proceedings, vol. 37, pp. 2329-2333, 2020.

[23] M. C. Nataraja, T. S. Nagaraj, and S. B. Basavaraja, "Reproportioning of steel fibre reinforced concrete mixes and their impact resistance," Cement and Concrete Research, vol. 35, no. 12, pp. 2350-2359, 2005.

[24] R. Kanagavel and A. Kalidass, "Mechanical Properties of hybrid fibre reinforced quaternary concrete," Građevinar, vol. 69, no. 1, pp. 1-10, 2017.

[25] P. Zhang, S. Han, S. Ng, and X.-H. Wang, "Fiber-Reinforced concrete with application in Civil engineering," Advances in Civil Engineering, vol. 2018, pp. 1-4, Article ID 1698905, 2018.

[26] Y. Wang, J. Chen, D. Gao, and E. Huang, "Mechanical properties of steel fibers and nanosilica modified crumb rubber concrete," Advances in Civil Engineering, vol. 2018, pp. 1-10, Article ID 6715813, 2018.

[27] Bureau of Indian Standards, Indian Standard Guidelines for concrete Mix Design Proportioning, Bureau of Indian Standards, New Delhi, India, 2009.

[28] Bureau of Indian Standards, Indian Standard Methods of Sampling and Analysis of Concrete, Bureau of Indian Standards, New Delhi, India, 1999.

[29] Bureau of Indian Standards, Indian Standard Methods of Tests for Strength of Concrete, Bureau of Indian Standards, New Delhi, India, 1999.

[30] Bureau of Indian Standards, Indian Standard Splitting Tensile Strength of Concrete- Method of Test, Bureau of Indian Standards, New Delhi, India, 1999.

[31] K. S. Elango and V. Revathi, "Mechanical and durability studies on pervious concrete using different types of binders," Romanian Journal of Materials, vol. 50, no. 2, pp. 258-267, 2020. 
[32] ACI Committee 544, "Measurement of Properties of Fiber Reinforced Concrete," American Concrete Institute, vol. 85, no. 6, pp. 583-593, 1998.

[33] R. Navilesh, S. P. Shankar, Vivekan, and A. Gutteder, "Study on hybrid fiber reinforced concrete," International Research Journal of Engineering and Technology, vol. 4, no. 6, 2017. 